\title{
The Geoelectric Structure of the Yamasaki and the Hanaori Faults, Southwest Japan
}

\author{
Shun Handa' and Norihiko Sumitomo \\ College of Liberal Arts, Kyoto University, Kyoto, Japan
}

(Received October 10, 1983; Revised September 3, 1984)

\begin{abstract}
Magnetotelluric surveys by using natural noises in the Schumann frequency band $(8-40 \mathrm{~Hz})$ were made to clarify the resistivity structure of two strike-slip type active faults, the Yamasaki and the Hanaori faults in southwest Japan. Micro-earthquakes are reported to occur frequently within narrow belts along them.

Broad low-resistivity zones were found along the Hanaori and the Yamasaki faults. Their widths are about $3 \mathrm{~km}$ for the Hanaori fault and about $6 \mathrm{~km}$ for the Yamasaki fault. Resistivity in the zone is smaller by 1 order of magnitude, relative to the surrounding earth. This fact suggests that the wide areas along the main axis of the two faults are weakly fractured and probably filled with water. The low-resistivity zone is a good indicator for a fault activity and its existence strongly suggests that the fault is active. The magnetotelluric method is one of the effective means to find such active faults.
\end{abstract}

\section{Introduction}

The Yamasaki and the Hanaori faults located in the inner zone of southwest Japan are strike-slip type active faults (Fig. 1). The mean velocity of the slip motion both in these faults is estimated to be about $0.3 \mathrm{~mm} /$ year on the basis of neotectonic studies (RESEARCH Group FOR ACTIVE FAUlTS, 1980). Microearthquakes have occurred very frequently within a narrow belt along the Yamasaki and the Hanaori faults at shallow depths below the crust, mostly at a depth of about $10 \mathrm{~km}$ (OIKE, 1976; WATANABE, 1980). In the Yamasaki fault, a lowresistivity zone was found along the fault by various kinds of geomagnetic and geoelectric surveys, such as direct current methods and electromagnetic induction techniques (Electromagnetic Research Group for the Active Fault (1982), hereafter referred to as ERGAF(1982)). ERGAF(1982) has pointed out that the low-resistivity zone has a three-fold structure, probably consisting of layers of different degree of fracture and of water content.

The purpose of this paper is to investigate the geoelectrical structure of the Hanaori and the Yamasaki faults by using the magnetotelluric (MT) method, one of the electromagnetic induction techniques. The MT method in audio-

\footnotetext{
${ }^{1}$ Now at College of Liberal Arts, Saga University, Saga, Japan.
} 


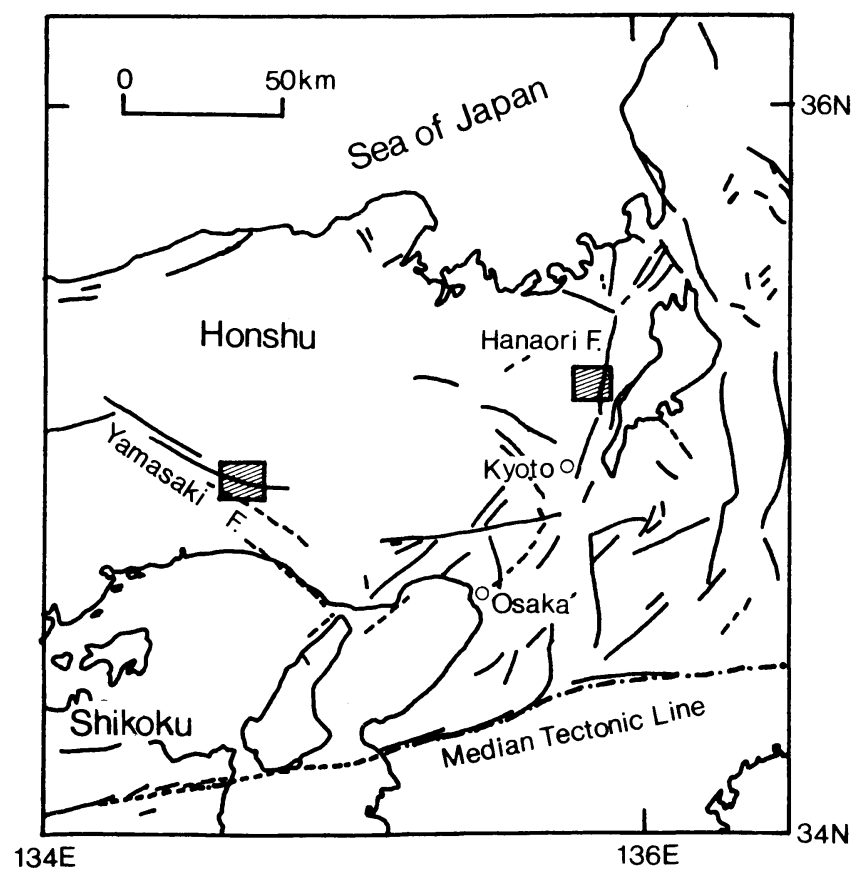

Fig. 1. Location of the magnetotelluric sounding areas. Distribution of the active faults (solid and broken lines) and the Median Tectonic Line (a chain line) are also illustrated.

frequency bands $(5 \mathrm{~Hz}-2 \mathrm{KHz})$ has been successfully applied to the soundings to detect conductors in the shallow part of the crust such as geothermal exploration (e.g., HoOver et al., 1978) and mineral exploration (e.g., Strangway et al., 1973). We have developed the equipment for the ELF-MT method using the Schumann resonance phenomena in the ELF frequency bands (HANDA and Sumitomo, 1979; Handa et al., 1980). The energy of the Schumann resonance originates in worldwide thunderstorm activities, with the principal energy produced from tropical storm cells. Since electric and magnetic fields of the Schumann resonance phenomena are continuously observed with fairly strong intensity at the resonant frequencies of 8,14 and $20 \mathrm{~Hz}$, these phenomena are suitable for the source of the MT-sounding. The maximum sounding depth of the MT method can be related to frequency by using the concept of the skin depth. In our ELFMT system, electric and magnetic fields are measured in the frequency range of 8 to $40 \mathrm{~Hz}$. Accordingly, the maximum skin depth is $1.8 \mathrm{~km}$ in $100 \mathrm{ohm}-\mathrm{m}$ earth and $18 \mathrm{~km}$ in $10,000 \mathrm{ohm}-\mathrm{m}$ earth material.

\section{ELF-MT System}

The ELF-MT system used in this study consists of a magnetometer, a telluric 
amplifier and a digital voltage meter. A block diagram of this system is shown in Fig. 2. The system is light and highly portable, and provides only scalar values of apparent resistivity. Telluric and magnetic fields are amplified and selected waves are taken out by the band-pass filters which have the peak response at frequencies of 8,14 and $20 \mathrm{~Hz}$. In order to obtain the value of apparent resistivity in the field, the envelopes of the wave forms in telluric and magnetic components are detected and displayed in digital forms simultaneously.

For the first portions of the ELF-MT survey in the Yamasaki fault, a prototype ELF-MT system was used. In this system, out put signals were recorded on a magnetic cassette tape. Apparent resistivities were calculated from the ratio of the power spectrum densities of telluric and magnetic fields.

\section{Apparent Resistivity Profiles across the Active Fault}

\subsection{Yamasaki fault}

The sites of the ELF-MT surveys and a simplified geological map in the Yamasaki fault are shown in Fig. 3. The fault runs over $80 \mathrm{~km}$ long and its strike is east-southeast in this area. Paleozoic sandstone and slate distribute along the fault. These rocks are in contact with rhyolite in the south of the fault. In the north of those sediments, rhyolite covers wide area which is supposed to have extruded during Late Cretaceous to Paleogene.

Sounding sites were selected to be located as far as possible from AC power transmission lines. Nevertheless, noises especially in the telluric component were so large at a few sounding sites near the main fault axis that observations were difficult. Noise currents probably flow concentratedly in the highly conductive zone along the main fault axis.

In Fig. 4, apparent resistivities for $H$-polarization (i.e., telluric field is perpendicular to the strike of the discontinuity) obtained at frequencies of 8,14 and $20 \mathrm{~Hz}$ are plotted against the distance from the main fault axis. The theoretical magnetotelluric response to a two-dimensional resistivity contrast shows that apparent resistivity varies smoothly for $E$-polarization (i.e., telluric component is parallel to the strike of the discontinuity), but discontinuously for $H$-polarization (e.g., Vozoff, 1972). In other words, the apparent resistivity profile for $H$ polarization is more sensitive to the lateral resistivity change than that for $E$ polarization is and the former indicates more accurately a location of the resistivity contrast.

It is clearly seen in Fig. 4 that the low-resistivity zone with typical apparent resistivity of about $500 \mathrm{ohm}-\mathrm{m}$ for $8 \mathrm{~Hz}$, extends laterally from the main fault axis about $4 \mathrm{~km}$ towards the north and about $2 \mathrm{~km}$ towards the south. Outside of this zone, apparent resistivities are relatively high, ranging from 20,000 to $30,000 \mathrm{ohm}-\mathrm{m}$. The resistivity decrease is very steep at the southern boundary of the zone but rather gradual at the northern part of the zone. The main fault, as presently defined on the surface by geological techniques, is not at a center of the low-resistivity zone, but its position is biased towards the southern edge 


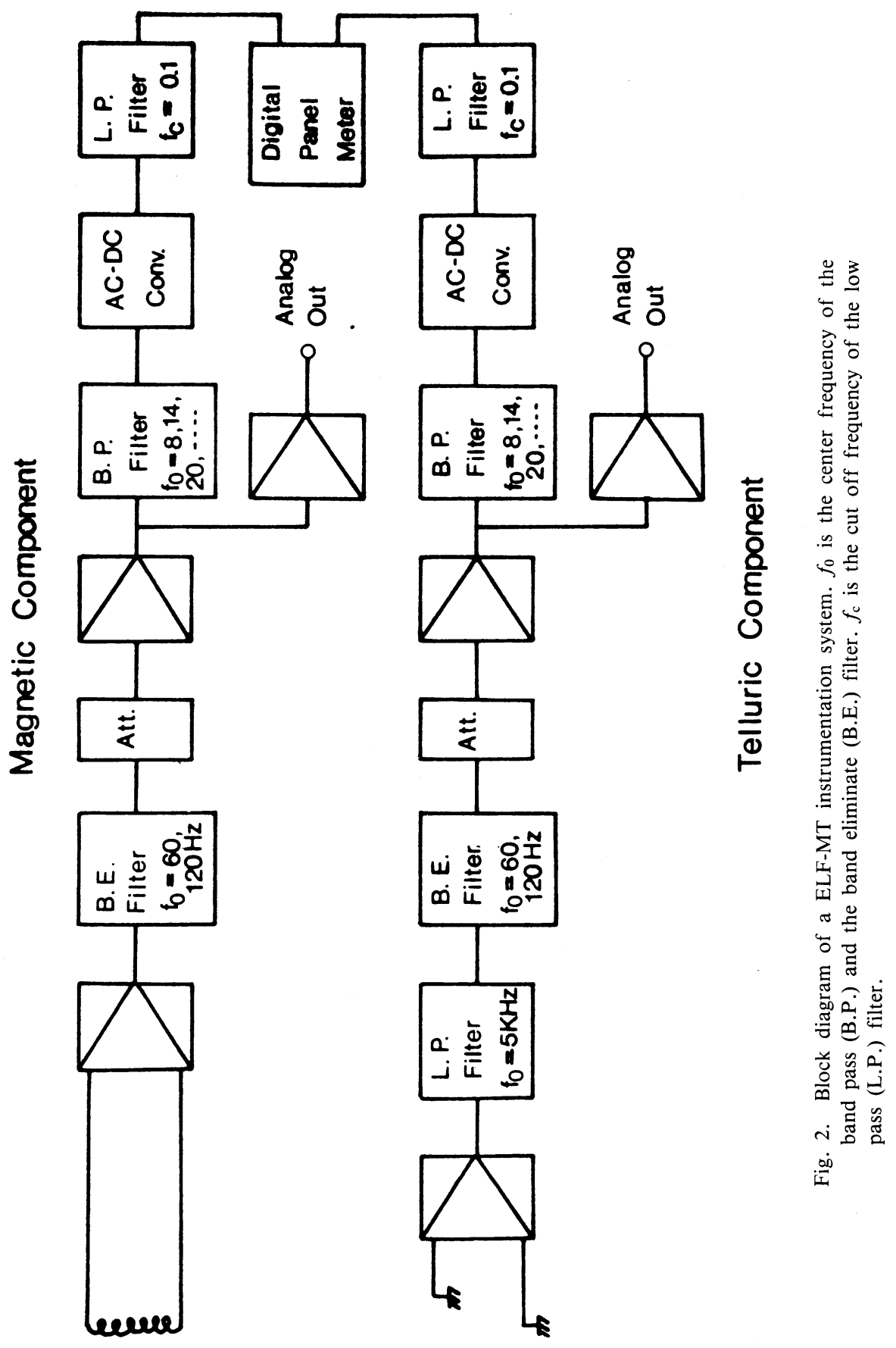




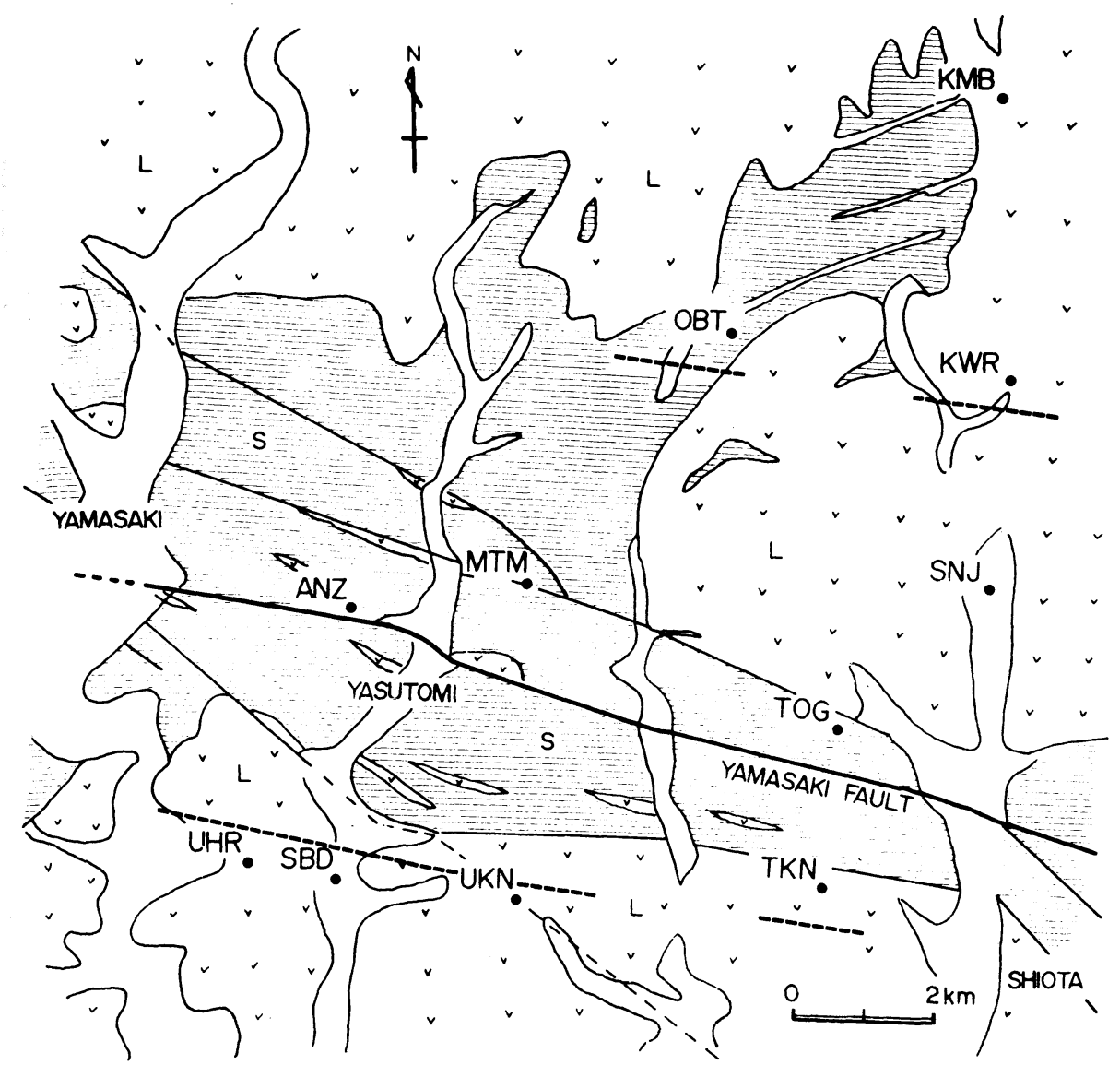

Fig. 3. Locations of the ELF-MT sounding sites and a simplified geological map around the Yamasaki fault. s; sandstone and slate. L; rhyolite. The main axis of the fault system is drawn with a thick solid line. Broken lines show the boundaries of the low-resistivity zone presumed by the present surveys.

of the zone. This asymmetric distribution of the low-resistivity zone with respect to the main fault axis is also seen in the resistivity profiles obtained by DC and VLF-MT surveys, where the sounding depth is limited up to about $1 \mathrm{~km}$ (ERGAF, 1982).

\subsection{Hanaori fault}

The Hanaori fault runs in the north-south direction along the geologic boundary between the Tamba zone and the Kinki Triangle (HuzITA, 1969). Its southern part passes through the east part of Kyoto city. The Hanaori fault can be clearly traced as a lineament along the River of Ado on aerial photos. The survey area 


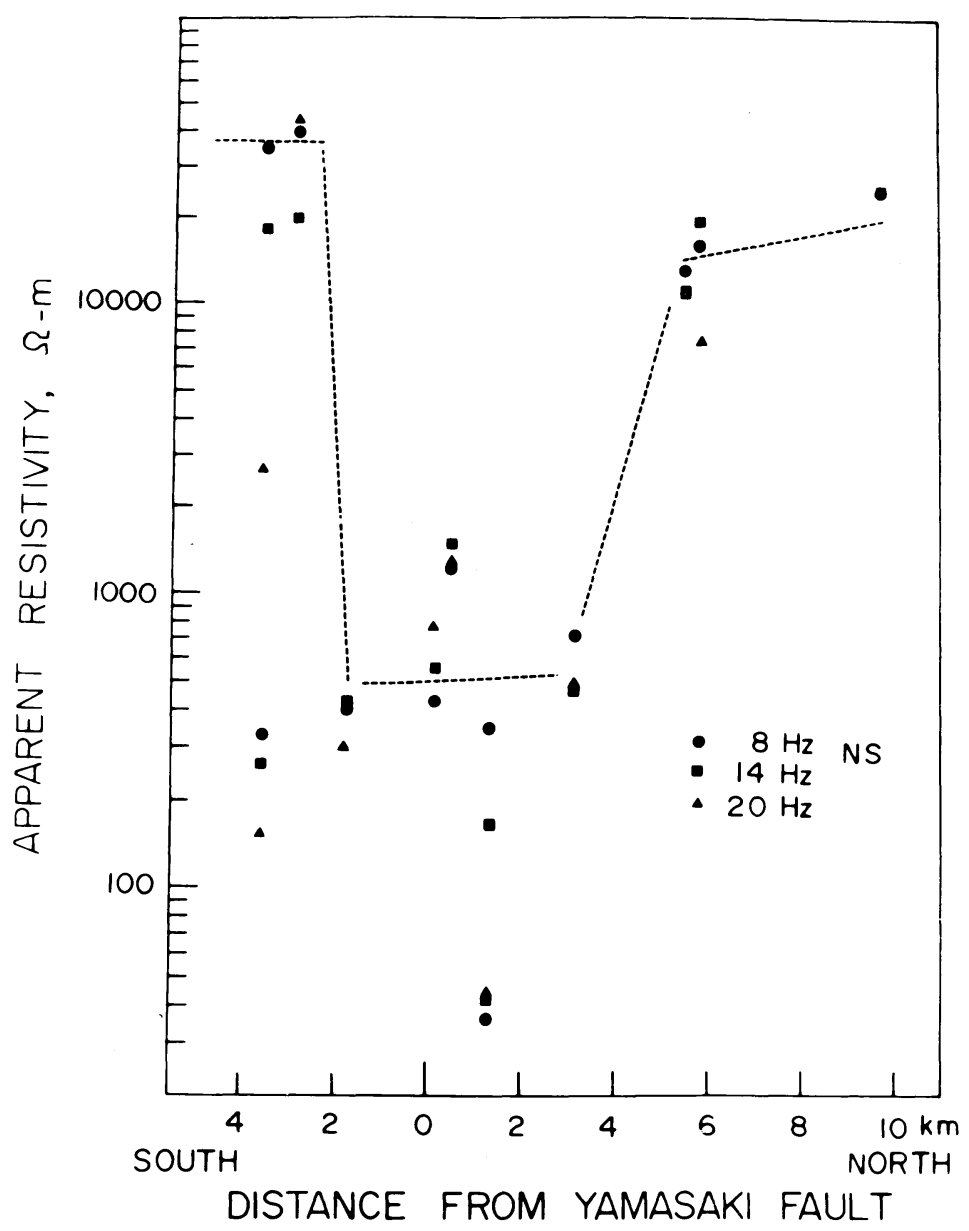

Fig. 4. North-south profile of apparent resistivity across the Yamasaki fault. Electric field was kept in direction of north-south. Circles, squares and triangles reperesent apparent resistivities for frequencies of 8,14 and $20 \mathrm{~Hz}$, respectively.

shown in Fig. 5 is located $20 \mathrm{~km}$ north of Kyoto city, away from an artificially noisy environment. This area is extensively comprized of Paleozoic sandstone, slate and chert of the Tamba zone. The total thickness of sedimentary layers is considered to be several kilo-meters. In the east of this area, Mesozoic granite is exposed.

The ELF-MT sounding was made at 20 sites which lay along the three eastwest lines crossing the fault. The distribution of the sounding site is shown in Fig. 5. The telluric line at each site was kept perpendicular to the strike of the fault. Considerable decreases in the resistivity values are found between sites A 4 and A7 and between A6 and A21 on line A, between sites $\mathrm{C} 1$ and $\mathrm{C} 3$ on 


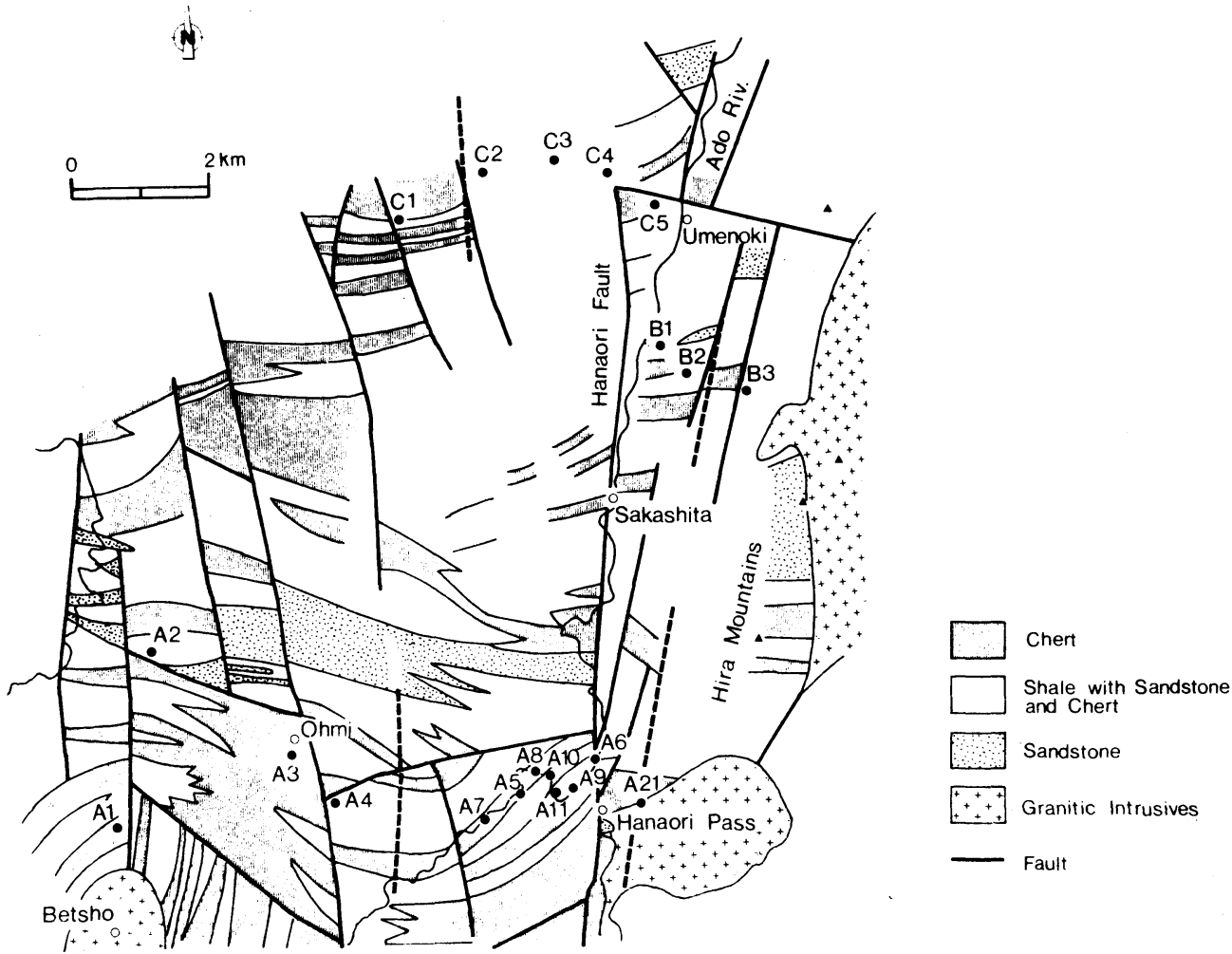

Fig. 5. Locations of the ELF-MT sounding sites and a geological map around the Hanaori fault after Geologic Map of the Tamba Belt compiled Tamba Belt Research Group (1974). Broken lines show the boundaries of the low-resistivity zone presumed by the present surveys.

line $\mathrm{C}$ and between B2 and B3 on line B (see Figs. 5 and 6). As the profile of apparent resistivity is similar on lines $\mathrm{A}$ and $\mathrm{C}$, the low-resistivity zone runs north to south along the main fault axis in this region. Though it may continue from $\mathrm{A}$ to $\mathrm{C}$ lines, only parts detected near sounding lines are illustrated by dashed lines in Fig. 5. The low-resistivity area extends mainly westward from the main fault axis as far as $3 \mathrm{~km}$. Thus, the distribution of apparent resistivity around the main fault axis is clearly asymmetric also in this fault.

\section{Resistivity Models for the Active Faults}

Interpretation is made through two stages as usual (e.g., Vozoff, 1972). In the first stage assuming a two or three layered model, one-dimensional resistivity distribution is obtained by inversion of the observed apparent resistivity result for each sounding. For this purpose, resistivity and thickness of the topmost layer are determined first by the additional DC-survey, because apparent resistivities 


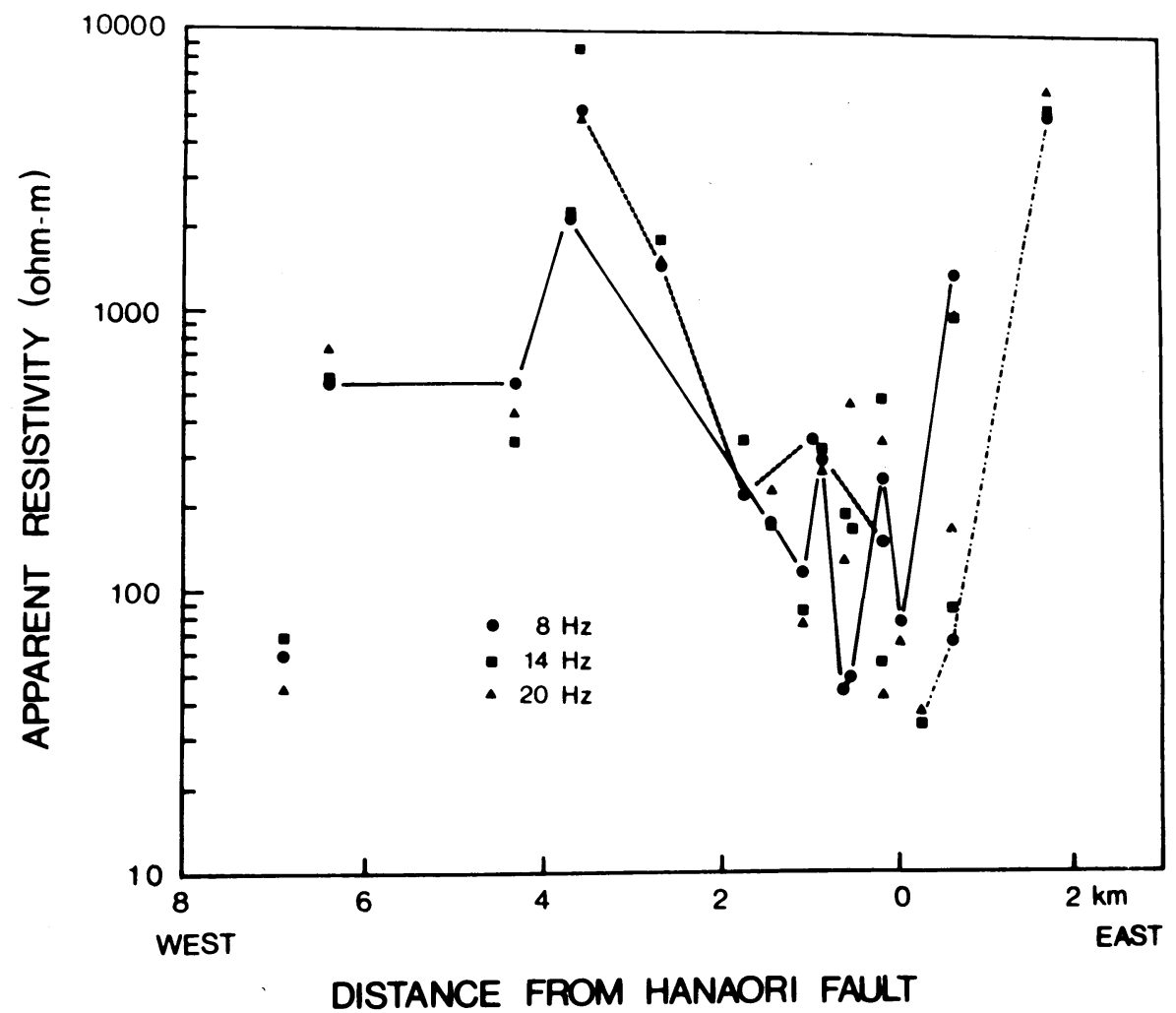

Fig. 6. East-west profiles of apparent resistivity across the Hanaori fault. Apparent resistivity profile is illustrated by the solid line on sounding line A, the broken line on line B and the chain line on line C. Electric field was kept in direction of east-west. Circles, squares and triangles represent apparent resistivities for frequencies of 8,14 and $20 \mathrm{~Hz}$ respectively.

in this survey are obtained only for three frequencies, which enabled us to determine resistivities and thicknesses of two or three layers only relatively. To determine the values of the topmost layer first is useful also from the reason that the $H$-polarization response is much influenced by the near-surface resistivity variations.

In the Yamasaki fault, the vertical soundings of the electrical resistivity had already been made around the low-resistivity zone (ERGAF, 1982). The topmost layer near the ELF-MT site of TOG inside of the low-resistivity zone has a typical resistivity of about $300 \mathrm{ohm}-\mathrm{m}$ and it continues to a depth more than 1,000 $\mathrm{m}$. This conductive layer, however, becomes thinner as we leave this site. The resistive layer of about 1,000 ohm-m appears at a depth of a few hundred meters, but the bottom depth of this layer could not be decided only from the DC-survey. Outside of the low-resistivity zone, the topmost layer has a resistivity value of about 
$700 \mathrm{ohm}-\mathrm{m}$. Its thickness is about $140 \mathrm{~m}$ near OBT but a few tens of meters near UKN. As the $700 \mathrm{ohm}-\mathrm{m}$ layer is fairly thin outside of the area near OBT, we disregarded this layer is constructing the two-dimensional model in the second stage.

In the Hanaori fault, near-surface resistivity values were determined by the Schlumberger method with the maximum spacing of $A B / 2=50 \mathrm{~m}$. The result shows that resistivity varies from 300 to $500 \mathrm{ohm}-\mathrm{m}$ at sites A7, A8 and A9 inside of the low-resistivity zone. Outside of the zone, it is high, larger than 2,000 ohm-m at B3.

In the second stage, a two-dimensional inversion process is performed. An initial two-dimensional model is constructed from the one-dimensional models obtained for each site in the first stage. Next, this model is adjusted so as to fit the observed resistivity profile obtianed for each frequency. In this process, fixed values obtianed by the DC-surveys are adopted for the topmost layer and the top of a semi-infinite conducting layer of $100 \mathrm{ohm}-\mathrm{m}$ is assumed at the depth of $25 \mathrm{~km}$. We have computed the $H$-polarization response of the two-dimensional resistivity structures by using a finite-element program with principles akin to those of REDDY and RANKIN (1975).

The final two-dimensional resistivity models of the Yamasaki and the Hanaori faults are presented in Figs. 7 and 8, respectively. The models explain the observation fairly well. The basic structure of the low-resistivity zone is considered to be the conductive "dike-like" body with resistivity of 1 order of magnitude smaller than the surrounding earth. However, this zone is rather wide, having a width of about $6 \mathrm{~km}$ in the Yamasaki fault and of about $3 \mathrm{~km}$ in the Hanaori fault. The bottom depths of this layer in the two faults are shown by a dashed line at a depth of $3 \mathrm{~km}$ in Fig. 7 and $1.5 \mathrm{~km}$ in Fig. 8. Though the resistivity models like those in Figs. 7 and 8 are non-unique, they are the most reasonable ones in use for the present technique. For example, in the case of the Yamasaki fault, when we set the bottom of the low-resistivity zone hallower than $3 \mathrm{~km}$, it makes apparent resistivities at all points inside of the zone unreasonably small. Thus such model must be abandoned. On the contrary, depths much more than $3 \mathrm{~km}$ for the Yamasaki and $1.5 \mathrm{~km}$ for the Hanaori faults are likely, but in the present paper the bottom was preliminarily shown there, considering the limitation of the maximum sounding depth in this MT method. Our result agrees with the earlier result that the low resistivity continues deeper than 1,000 m near the Yamasaki main fault (ERGAF, 1982).

Within the low-resistivity zone, some anomalies are found both in the Yamasaki and Hanaori faults where resistivity is much smaller than the surrounding region. They are shown as the 100-300 ohm-m area for the Yamasaki fault model in Fig. 7 and as the $30-100$ ohm-m area for the Hanaori fault model in Fig. 8. They seem to be located just beneath the fault. These may correspond to the "highly localized high conductivity anomaly" discussed by ERGAF(1982). ERGAF(1982) concluded that the high conductivity of this anomaly is due to the water saturated clayish minerals. 


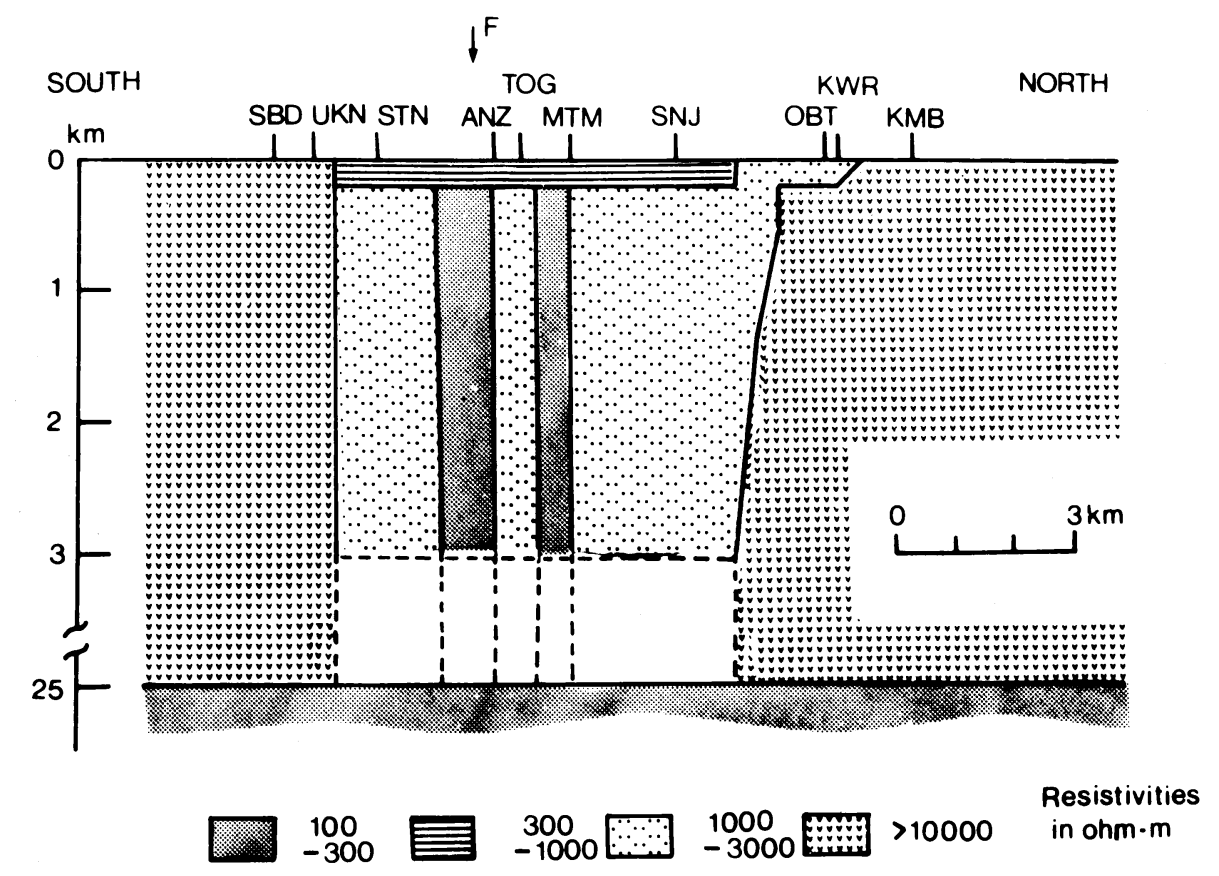

Fig. 7. Two-dimensional model for the Yamasaki fault. The position of the main fault axis is shown by an arrow and a letter symbol of $\mathrm{F}$. The dotted lines represent uncertain boundaries.

\section{Discussions}

The resistivity models for the Hanaori and the Yamasaki faults clearly show the existence of a broad low-resistivity zone of several kilo-meters in width. In the Yamasaki fault, Paleozoic sedimentary rocks cover the wide area along the main fault axis. The high conductivity of the low-resistive zone seems to be associated with the distribution of Paleozoic sedimentary rocks. As resistivity of sedimentary rocks, in general, is lower than that of igneous rocks, it seems reasonable that the low-resistivity anomaly is caused by the difference in resistivity between the sedimentary and the igneous rocks. However, resistivity is high at OBT which is still located inside the sedimentary rock area. On the contrary, resistivity is low at TKN which is south of the sedimentary rock area. In the upper crust, high conductive anomalies are very frequently caused by the water saturation in rocks. An increase in water content decreases resistivity in rocks (PARKhomenko, 1967). ERGAF(1982) discussed the causes of the low-resistivity anomaly in the Yamasaki fault and concluded that the main cause of the low resistivity does not exist in the difference in the rock type but in the mechanical property characteristic of the fault region. In other words, it is caused by the fact that rocks are fractured by fault activity and become porous. The presence 


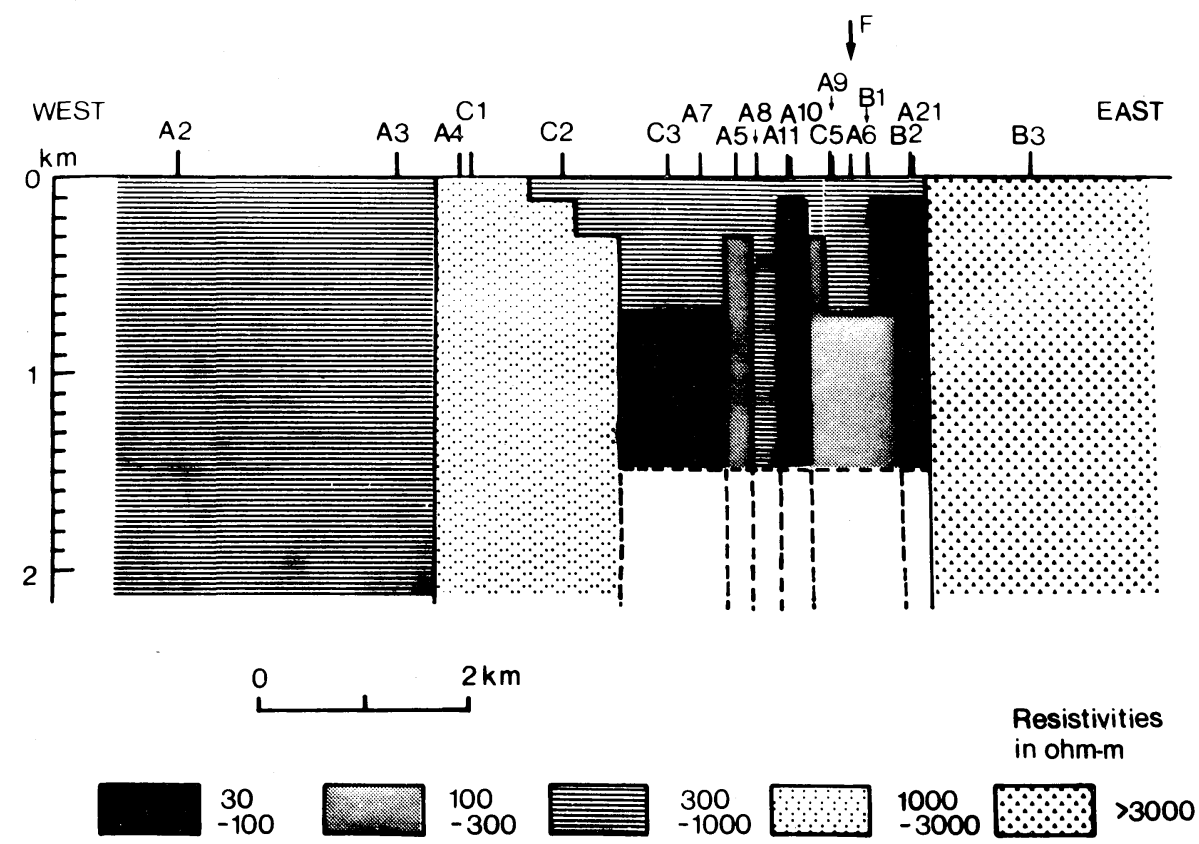

Fig. 8. Two-dimensional model for the Hanaori fault. The position of the main fault axis is shown by an arrow and a letter symbol of $\mathrm{F}$. The dotted lines represent uncertain boundaries.

of the wide resistivity zone in the Hanaori fault strongly reinforces this interpretation. As mentioned in Section 3.2, the survey area in the Hanaori fault is extensively comprized of Paleozoic sedimentary rocks (see Fig. 5). It is not natural to consider that considerable lateral change in resistivity as shown in Fig. 6 is originated only from the difference in rock type (i.e., chert, slate and sandstone). Thus, we can conclude that the broad region fractured by fault activities might be filled with water and is detected as the wide low-resistivity zone both in the Yamasaki and the Hanaori faults.

Is the wide low-resistivity zone formed solely by the activity of a single fault? It is natural that this zone is an ensemble of the zones fractured by several activities of individual faults which constitute an active fault system. However, the active fault is not found at the northern part of the low-resistivity zone in the Yamasaki fault, even though resistivity is low at this part. Generally, fractures in rocks are re-produced incessantly by the fault activity while the fault is active. However, compressive stress closes fractures, once the fault ceases its activity. Significant microcrack closure in some rocks is observed directly with a scanning electron microscope at the low stress of less than 300 bar (BATZLE et al., 1980). Laboratory experiments also indicate that resistivity of the rocks saturated with water significantly increases with pressure (e.g., BRACE et al., 
1965). Since electrical conduction in saturated rocks takes place through motion of ions, resistivity of the rock increases, when cracks are closed by compressive stress and then conducting paths decrease in cross section (BRACE et al., 1965). The Yamasaki and the Hanaori faults are supposed to have been active since some time in the Quarternary period. It is quite possible that the regional stress patterns in these regions have changed through this period, and some faults in the two fault systems have ceased their activity. The northern part of the lowresistivity zone in the Yamasaki fault and the western part in the Hanaori fault may be in the recovery phase to high resistivity by closing fractures as the active part of the fault system migrates laterally. The part of the "localized high conductivity anomalies" beneath the faults may be active now. This idea is supported by asymmetric distributions of the resistivity with respect to the main fault axis.

From the discussion mentioned above, it is also concluded that the existence of the low-resistivity zone indicates fault activity. An example is seen in the following case where no clear resistivity change is found at the presumed position of the active fault. In the east part of Shikoku Island, the Median Tectonic Line (MTL) fault makes up a system constituted of several faults. One of them is the boundary fault between the Izumi Group and the Sanbagawa metamorphic belt. The others are the faults running parallel to the boundary fault in the Izumi Group (OKADA, 1973). All of them are considered to be the active fault. MATSUDA (1973) has, however, pointed out that the geologic boundary fault in the MTL fault system is less or not active in the Kinki district. The ELF-MT surveys made across the MTL in the east part of Shikoku Island indicated that at least two narrow low-resistivity belts stand in the Izumi Group, but any clear resistivity changes can not be found at the presumed location of the geologic boundary fault (HANDA and TAMADA, 1981). In this case, the boundary fault in the MTL fault system may have ceased its activity and the active region has migrated to the area of the Izumi Group.

Finally, we will briefly discuss the possible relationship between seismicity and the low-resistivity zone in the two faults. Some seismic events which occurred surrounding the Yamasaki fault are reported to be related to precipitation (Oike and Kishimoto, 1976; Oike, 1977; Kishimoto, 1980). Preceding the earthquake $(M=3.9)$ on September 28, 1979, a decrease of Chloride ion content was observed at the Shiota hot spring (Fig. 3) south of the Yamasaki main fault (YOSHIOKA, 1980). These evidences imply that some seismic events in this area are possibly related to the underground water, while it is very speculative to consider that the underground water penetrates into the crust to a depth of 15 $\mathrm{km}$. The locations of seismic foci are determined very accurately in this area (OIKE and Kishimoto, 1976). They seem to be localized limitedly in the narrow belt between the lines at several kilo-meters north and several hundred meters south of the Yamasaki fault axis (Mino, private communication). This seems to imply some relationship between the low-resistivity zone and seismicity.

In the Hanaori fault, epicenters of the micro-earthquakes appear to distribute in the Tamba Zone west of the fault (Mino, private communication), where the low-resistivity zone has a width of over $2 \mathrm{~km}$. 


\section{Concluding Remarks}

The resistivity structures of the active fault are studied in this paper. The low-resistivity zone, of which resistivity is smaller by 1 order of magnitude as compared with the surrounding earth has a width of about $6 \mathrm{~km}$ in the Yamasaki fault and that of about $3 \mathrm{~km}$ in the Hanaori fault. The main fault tends to have shifted its position to the side having a large resistivity gradient. The lowresistivity zone is possibly due to rocks fractured by the fault activity and filled with water. Its existence is closely related to a fault activity and is a good indicator of active faults. Surveys for much more active faults, however, should be needed in order to confirm this hypothesis.

The magnetotelluric technique used is useful for detecting a fracturing of high conductive layer associated with a fault. Throughout the observation, it was shown that the equipment used was easy to transport and measurements can be performed relatively quickly.

We would like to express many thanks to the memebers of the Electromagnetic Research Group for the Active Fault for helping the surveys and useful discussions. We thank Mr. T. Mogi for computer programs of the finite element method used in the interpretation and helping the surveys. We benefited from stimulating discussions with Mr. K. Mino and K. Watanabe of the Disaster Prevention Research Institute, Kyoto University and Dr. O. Tamada of Kyoto University. We also thank Dr. A. Suzuki of Saga University for a critical reading of this manuscript. The computation of the magnetotelluric responses to the model was carried out on FACOM 150F at the Computing Center of Saga University.

\section{REFERENCES}

BAtzle, M. L., G. Simmons, and R. W. SiEgFried, Microcrack closure in rocks under stress: Direct observation, J. Geophys. Res., 85, 7072-7090, 1980.

BRACE, W. F., A. S. ORANGE, and T. R. MADDEN, The effect of pressure on the electrical resistivity of water-saturated Crystalline rocks, J. Geophys. Res., 70, 5669-5678, 1965.

Electromagnetic ReSEARCH GROUP FOR THE ACTIVE FAUlt, Low electrical resistivity along an active fault, the Yamasaki fault, J. Geomag. Geoelectr., 34, 103-127, 1982.

HANDA, S. and N. SUMITOMO, MT-sounding around active fault by using natural electromagnetic noises in the ELF range: Yamasaki fault, Tsukumo Earth Sci., 14, 21-31, 1979. (in Japanese)

HANDA, S. and O. TAMADA, Observation of earth resistivity at median tectonic line: Application of ELF-MT method to Northeastern Shikoku District, Tsukumo Earth Sci., 16, 1-5, 1981. (in Japanese)

HANDA, S., O. TAMADA, and N. SUMITOMO, MT-sounding around active fault by using natural electromagnetic noises in the ELF range: Hanaori fault (1), Tsukumo Earth Sci., 15, 50-56, 1980. (in Japanese)

Hoover, D. B., C. L. LONG, and R. M. SEnTERfit, Some results from audiomagnetotelluric investigations in geothermal areas, Geophys, 43, 1501-1514, 1978.

Huzita, K., Tectonic development of Southwest Japan in the Quaternary Period, J. Geosci. Osaka City Univ., 12, 53-70, 1969.

Kishimoto, Y., Test-field experiments for earthquake prediction at the Yamasaki fault, in Proc. Earthq. Prediction Res. Symposium (1980), pp. 133-142, Subcommittee Earthq. Prediction and Seism. Soc. Japan, 1980. (in Japanese) 
MATSUDA, T., The median Tectonic Line as an active strike-slip fault system, in Median Tectonic Line, edited by Sugiyama R., pp. 239-251, Tokai Univ. Press, Tokyo, 1973. (in Japanese)

OIKE, K., Spatial and temporal distribution of micro-earthquakes and active faults, Memoirs. Geolog. Soc. Japan, 12, 59-73, 1976.

OIKE, K., On the relation between rainfall and the occurrence of earthquakes, Ann. Rep. Disaster Prev. Res. Inst., Kyoto Univ., 20, 35-45, 1977.

OIKE, K. and Y. KISHIMOTO, The Yamasaki fault as a testfield for the earthquake prediction, in Proc. Earthq. Prediction Res. Symposium (1976), pp. 83-90, Subcommittee of Earthq. Prediction and Seism. Soc. Japan, 1976. (in Japanese)

OKADA, A., On the Quaternary faulting along the Median Tectonic Line, in Median Tectonic Line, edited by Sugiyama R., pp. 49-86, Tokai Univ. Press, Tokyo, 1973. (in Japanese)

PARKHOMeKo, E. I., Electrical Properties of Rocks, pp. 119-128, Plenum Press, New York, 1967.

REDDY, I. K. and D. RANKIN, Magnetotelluric response of laterally inhomogeneous and anisotropic media, Geophys., 40, 1035-1045, 1975.

RESEARCH GROUP FOR ACTIVE FAUlt, Active Faults in Japan: Sheet and Inventories, pp. 225-239, Univ. of Tokyo Press, 1980.

Strangway, D. W., C. M. Swift, Jr., and R. C. Holmer, The application of audio-frequency magnetotellurics (AMT) to mineral exploration, Geophys., 38, 1159-1175, 1973.

VOzofF, K., The magnetotelluric method in the exploration of sedimentary basins, Geophys., 37, $98-141,1972$

Watanabe, K., Geological structure and microseismicity in the Hokuriku District, Zishin, 33, 79-89, 1980. (in Japanese)

YoSHIOKA, R., Relation between Chloride ion content in Shiota hot spring near the Yamasaki fault and small earthquakes in its vicinity, in Proc. Earthq. Prediction Res. Symposium (1980), pp. 159-162, Subcommittee Earthq. Prediction and Seism. Soc. Japan, 1980. (in Japanese) 